\title{
Pulmonary arterial pressure during rest and exercise in healthy subjects: a systematic review
}

\author{
G. Kovacs*, A. Berghold ${ }^{*}$, S. ScheidI* and H. Olschewski*
}

ABSTRACT: According to current guidelines, pulmonary arterial hypertension (PAH) is diagnosed when mean pulmonary arterial pressure $\left(\bar{P}_{\mathrm{pa}}\right)$ exceeds $25 \mathrm{mmHg}$ at rest or $30 \mathrm{mmHg}$ during exercise. Issues that remain unclear are the classification of $\bar{P}$ pa values $<25 \mathrm{mmHg}$ and whether $\bar{P}_{\text {pa }}>\mathbf{3 0} \mathbf{~ m m H g}$ during exercise is always pathological.

We performed a comprehensive literature review and analysed all accessible data obtained by right heart catheter studies from healthy individuals to determine normal $\bar{P}_{\text {pa }}$ at rest and during exercise. Data on 1,187 individuals from 47 studies in 13 countries were included. Data were stratified for sex, age, geographical origin, body position and exercise level.

$\bar{P}_{\text {pa }}$ at rest was $14.0 \pm 3.3 \mathrm{mmHg}$ and this value was independent of sex and ethnicity. Resting $\bar{P}$ pa was slightly influenced by posture (supine $14.0 \pm 3.3 \mathrm{mmHg}$, upright $13.6 \pm 3.1 \mathrm{mmHg}$ ) and age (<30 yrs: $12.8 \pm 3.1 \mathrm{mmHg} ; 30-50$ yrs: $12.9 \pm 3.0 \mathrm{mmHg} ; \geqslant 50$ yrs: $14.7 \pm 4.0 \mathrm{mmHg}$ ). $\bar{P}_{\mathrm{pa}}$ during exercise was dependent on exercise level and age. During mild exercise, $\bar{P}_{\text {pa }}$ was $19.4 \pm 4.8 \mathrm{mmHg}$ in subjects aged $<50$ yrs compared with $29.4 \pm 8.4 \mathrm{mmHg}$ in subjects $\geqslant 50$ yrs $(p<0.001)$.

In conclusion, while $\bar{P}$ pa at rest is virtually independent of age and rarely exceeds $20 \mathrm{mmHg}$, exercise $\bar{P}_{\mathrm{pa}}$ is age-related and frequently exceeds $30 \mathrm{mmHg}$, especially in elderly individuals, which makes it difficult to define normal $\bar{P}$ pa values during exercise.

KEYWORDS: Exercise, pulmonary artery pressure, pulmonary hypertension, reference values, review, right heart catheterisation

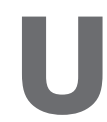
nder physiological circumstances, the pulmonary circulation is characterised by low pressure and low vascular resistance. Several pathological conditions are associated with increased pulmonary pressure, i.e. pulmonary hypertension (PH). PH may be classified as pulmonary arterial hypertension $(\mathrm{PAH})$ or $\mathrm{PH}$ due to a variety of causes including left heart diseases, lung diseases or pulmonary thromboembolic disease [1]. PAH is characterised by the absence of the latter causes and may be idiopathic, familial or associated with a number of other conditions.

According to the current European Society of Cardiology guideline, $\mathrm{PH}$ has been haemodynamically defined as a mean pulmonary artery pressure $(\bar{P}$ pa $)>25 \mathrm{mmHg}$ at rest or $>30 \mathrm{mmHg}$ during exercise [2]. The available data, however, suggests that normal resting $\bar{P}_{\text {pa }}$ is considerably lower than
$25 \mathrm{mmHg}$, usually $<21 \mathrm{mmHg}$ [3-5]. Several studies in patients with chronic obstructive pulmonary disease or interstitial lung disease have suggested

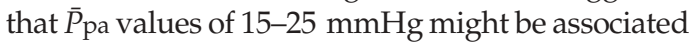
with adverse events and impaired outcome [6-8].

Although exercise haemodynamics have been included in the haemodynamic definition of $\mathrm{PH}$, it does not account for factors such as exercise level, exercise method, position and age that may have an impact on $\bar{P}_{\text {pa. }}$.

This literature review was conducted to summarise the available data that have been obtained from healthy individuals to define normal values of $\bar{P}$ pa during rest and exercise. We considered factors that might have an impact on $\bar{P}$ pa, such as posture, workload, age, geographic origin and sex. We found that the normal range of resting $\bar{P}_{\text {pa }}$ is considerably lower than $25 \mathrm{mmHg}$, while

For editorial comments see page $\mathbf{7 9 0}$.

This article has supplementary material accessible from www.erj.ersjournals.com

\section{AFFILIATIONS}

*Dept of Pulmonology, and

\# Institute for Medical Informatics, Statistics and Documentation, Medical University of Graz, Graz, Austria.

\section{CORRESPONDENCE}

H. Olschewski

Dept of Pulmonology

Medical University Graz

Auenbruggerplatz 20

8036 Graz

Austria

E-mail: horst.olschewski@

meduni-graz.at

Received:

Sept 242008

Accepted after revision:

March 062009

First published online:

March 262009 
exercise values, particularly in individuals aged $>50 \mathrm{yrs}$, often exceed $30 \mathrm{mmHg}$.

\section{METHODS: SEARCH STRATEGY, SELECTION CRITERIA AND STRATIFICATION}

Publications examining pulmonary arterial pressure values during both rest and physical exercise in healthy volunteers were identified by a Medline search using the keywords "pulmonary arterial pressure and exercise", "right heart catheterisation and exercise" and "right heart catheter and exercise". The search was restricted to papers available in the English, German or French languages. A secondary search reviewed the reference lists of relevant papers (mostly not available in Medline). This secondary hand search identified the majority of included studies. Two reviewers (G. Kovacs and $\mathrm{H}$. Olschewski) independently screened the studies identified by the two searches. Differences over inclusion of studies were resolved by consensus reached after discussion.

All publications working up original data based on right heart catheterisation were included. Studies were excluded when they were referring to and interpreting previous examinations, or when the original data were not clearly identifiable, as well as when they did not provide detailed descriptions of the applied methods or complete haemodynamic data, or when drug-induced changes of pulmonary pressure were investigated. From studies examining pulmonary haemodynamics at high altitude or under hypoxic conditions, only the control measurements performed at sea level and under normal oxygen tension were considered. All subjects in all studies were described as entirely free of clinical symptoms, or had minor medical conditions that, according to the authors, had no influence on pulmonary haemodynamics.

The Medline search identified a total of 1,932 studies. According to the selection criteria, 138 studies were retrieved for more detailed evaluation and 16 studies were ultimately found to be eligible for inclusion. The reasons for exclusion were as follows: not only healthy subjects (38 studies); no original data (10 studies); no right heart catheterisation or no pulmonary arterial pressure measurements (72 studies); case report (two studies). After the secondary hand search, 31 further studies were found to be eligible and were included in the final analysis. Altogether data from 47 studies published in the English, German and French literature between 1947 and 2003 were reviewed, which included 72 separate study populations [9-58].

The majority of studies used cycle ergometry, but some studies used treadmill exercise, leg or arm presses in the supine or upright position. The investigations were performed in different populations (younger or older, untrained or trained, female or male preponderance) in different countries. Data were stratified upon predefined criteria including sex, age $(<30 \mathrm{yrs}, 30-50 \mathrm{yrs}$, $\geqslant 50 \mathrm{yrs}$ ), origin (USA, Europe), body position (supine, upright) and exercise level. Three exercise levels were distinguished (slight, submaximal and maximal exercise), and the data were assigned to these categories, according to the following hierarchical criteria: 1) the original assessment by the authors; 2) heart rate (slight: 100-110 $\mathrm{min}^{-1}$, submaximal: $130-135 \mathrm{~min}^{-1}$, maximal: $\left.160-170 \mathrm{~min}^{-1}\right)$; 3) work-rate (slight: $\sim 50 \mathrm{~W}$, submaximal: $\sim 100 \mathrm{~W}$, maximal: $\sim 150-200 \mathrm{~W}) ; 4$ ) peak oxygen uptake (slight: $\sim 1,000 \mathrm{~mL} \cdot \mathrm{min}^{-1}$, submaximal: $\sim 1,400-1,600 \mathrm{~mL} \cdot \mathrm{min}^{-1}$, maximal: $\sim 2,100-2,400 \mathrm{~mL} \cdot \mathrm{min}^{-1}$ ); and 5) cardiac output (slight: $\sim 12-14 \mathrm{~L} \cdot \mathrm{min}^{-1}$, submaximal: $\sim 16 \mathrm{~L} \cdot \mathrm{min}^{-1}$, maximal: $\sim 19$ $\left.20 \mathrm{~L} \cdot \mathrm{min}^{-1}\right)$. Owing to variations between study protocols, not all subjects were examined at all stages of exercise. Time points 2-3 min after start of a certain workload were considered for this analysis.

In some protocols, light sedation was applied before right heart catheterisation. These studies were included, as a previous review of a large database showed that such pre-medication may decrease systemic arterial pressure values, but has no significant impact on pulmonary haemodynamics [5].

Studies performed in the supine position were evaluated separately from studies in the upright position (sitting/ exercising on the cycle ergometer, standing/walking on the treadmill). Few investigations involved the same subjects in the supine and upright positions. The comparison of haemodynamics depending on posture in these studies was analysed separately.

The association between sex and $\bar{P}$ pa was examined in studies in which both females and males were included and the results given according to sex.

Data originating from Europe, the USA and other parts of the world were compared to exclude bias due to geographical location.

In most studies, the zero level was set at $10 \mathrm{~cm}$ above the table (or $5 \mathrm{~cm}$ below the level of the sternum). For a few subjects ( $\sim 10 \%$ of all subjects) a slightly different levelling was used (e.g. the mid-axillary line).

The recorded data were not reported uniformly in the original publications. Some authors gave the mean values and the standard deviation of parameters for the whole group $(\sim 70 \%$ of all subjects), with or without describing individual results; in other studies, only individual data were presented $(\sim 30 \%$ of all subjects). In these cases, the present authors calculated the mean values and standard deviations. The number of study populations (e.g. males and females, different age groups, when independently evaluated) and subjects examined for each particular variable at the given exercise level are indicated.

For the final analysis, the weighted mean and the weighted standard deviation values for the whole population reviewed were calculated. To evaluate the effect of position, sex and age at rest and during exercise, subgroup analysis was performed using only those studies in which the results were given according to these variables. A random effects model was used for the meta-analysis (StataCorp, College Station, TX, USA). To further describe the impact of age on pulmonary arterial pressure during exercise, a meta-regression analysis was performed comparing the haemodynamic data for all subjects aged $<50 \mathrm{yrs}$ with those aged $\geqslant 50 \mathrm{yrs}$. To explore the robustness of the results, pre-planned sensitivity analysis of geographical location and exercise method was performed. Upper limits of normal (ULN) were calculated as mean+2sD.

\section{RESULTS}

Tables 1-2 and figures 1-3 contain the most important results from the 47 publications included, describing 72 individually 


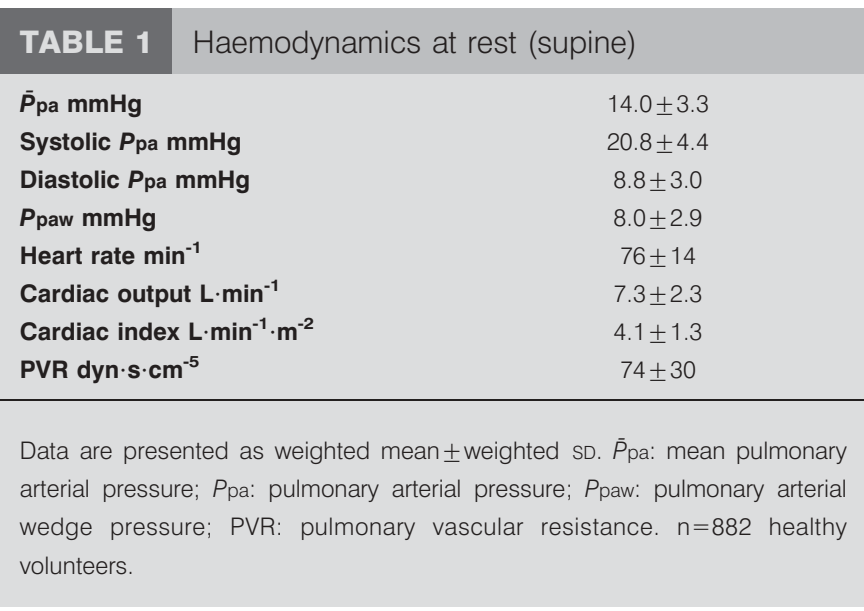

evaluated populations, altogether comprising 1,187 subjects (225 females, 717 males, no sex data for 245 subjects). The short description of all included studies (table A) and further haemodynamic analysis (tables B-K) are provided in the online data supplement.

\section{Mean and systolic pulmonary arterial pressure at rest: upper limit of normal}

$\bar{P}_{\text {pa }}$ and the most important haemodynamic variables at rest are shown in table 1. Data from the upright measurements and exercise data from all studies are shown in the online data supplement (tables B and C).

Based on the reviewed studies, resting $\bar{P}_{\text {pa }}$ is $14.0 \pm 3.3 \mathrm{mmHg}$ in the supine (based on data from 882 subjects) and $13.6 \pm 3.1 \mathrm{mmHg}$ in the upright position $(\mathrm{n}=301)$ (fig. 1). Consequently, the ULN would be $20.6 \mathrm{mmHg}$ in the supine and $19.8 \mathrm{mmHg}$ in the upright position.

The corresponding resting systolic pulmonary arterial pressure is $20.8 \pm 4.4 \mathrm{mmHg}$ in the supine $(\mathrm{n}=625$, ULN $29.6 \mathrm{mmHg}$ ), and $20.9 \pm 4.4 \mathrm{mmHg}$ in the upright position $(\mathrm{n}=241$, ULN $29.7 \mathrm{mmHg}$ ).

\section{Pulmonary arterial pressure during exercise}

As a response to exercise, $\bar{P}$ pa, heart rate and cardiac output increased. As the studies used different exercise protocols, $\bar{P}_{\text {pa }}$ during exercise was evaluated by analysing those studies in which the subjects were examined at rest and at least two different exercise levels [10, 26, 32, 47, 52, 53, 55]. According to

\begin{tabular}{lccc} 
TABLE 2 & Haemodynamics during upright exercise \\
& Rest & Slight & Maximal \\
\hline & & & \\
$\bar{P}_{\text {pa } \mathbf{~ m m g ~}}$ & $13.8 \pm 3.1$ & $20.8 \pm 4.0$ & $25.6 \pm 5.6$ \\
Ppaw $\mathbf{~ m H g}$ & $5.9 \pm 2.8$ & $9.1 \pm 4.2$ & $14.9 \pm 7.9$ \\
Heart rate min $^{-1}$ & $82 \pm 16$ & $103 \pm 14$ & $170 \pm 14$ \\
Cardiac output L. min $^{-1}$ & $7.4 \pm 2.2$ & $14.9 \pm 3.9$ & $20.0 \pm 3.8$ \\
\hline
\end{tabular}

Data are presented as weighted mean \pm weighted SD. $\bar{P}$ pa: mean pulmonary arterial pressure; Ppaw: pulmonary arterial wedge pressure. $n=193$ healthy volunteers. these studies, $\bar{P}$ pa increase during exercise corresponded to the increase in cardiac output (fig. 2).

Based on this group of patients, the ULN of $\bar{P}_{\mathrm{pa}}$ in the upright position was $28.8 \mathrm{mmHg}$ during slight and $36.8 \mathrm{mmHg}$ during maximal exercise (table 2). In studies where individual values were available, a total of 20 out of $97(21 \%)$ subjects (aged $<50$ yrs) reached $\bar{P}_{\text {pa values }}>30 \mathrm{mmHg}$ during maximal exercise.

\section{The influence of age on $\overline{\mathrm{P}}$ pa at rest and during exercise}

Several studies have addressed the effect of age on pulmonary arterial pressure during rest and exercise by comparing different age groups (<30 yrs, 30-50 yrs, $>50$ yrs) (fig. 3) [42, $48,50]$

Although the differences were small at rest, $\bar{P}_{\text {pa }}$ was significantly higher in subjects aged $\geqslant 50$ yrs compared with younger subjects $(\mathrm{p}<0.001)$. The mean values were $14.7 \pm 4.0 \mathrm{mmHg}, 12.9 \pm 3.0 \mathrm{mmHg}$ and $12.8 \pm 3.1 \mathrm{mmHg}$ in subjects aged $\geqslant 50 \mathrm{yrs}, 30-50 \mathrm{yrs}$ and $<30 \mathrm{yrs}$, respectively. There was no significant difference $(\mathrm{p}=0.64)$ between the $<30$ yr-old and 30-50-yr-old age-groups.

During slight exercise, $\bar{P}$ pa was significantly higher in subjects aged $\geqslant 50$ yrs compared with younger subjects $(\mathrm{p}<0.001)$. The mean values were $29.4 \pm 8.4 \mathrm{mmHg}, 20.0 \pm 4.7 \mathrm{mmHg}$ and $18.2 \pm 5.1 \mathrm{mmHg}$ in subjects aged $\geqslant 50 \mathrm{yrs}, 30-50 \mathrm{yrs}$ and $<30$ yrs, respectively (fig. 3 ) The combined $\bar{P}_{\text {pa }}$ of the $<30$ yr-old and 30-50-yr-old age-groups was $19.4 \pm 4.8 \mathrm{mmHg}$, so the ULN for $\bar{P}_{\text {pa }}$ in individuals aged $<50$ yrs would be $29.0 \mathrm{mmHg}$, while in subjects aged $\geqslant 50 \mathrm{yrs}$ it would be $46.2 \mathrm{mmHg}$. As only a few subjects aged $\geqslant 50$ yrs were examined at higher exercise levels, reliable statistical analysis was not possible.

\section{Pulmonary arterial wedge pressure, cardiac output and pulmonary vascular resistance}

Although the primary objective of this study was pulmonary arterial pressure, other haemodynamic parameters were also

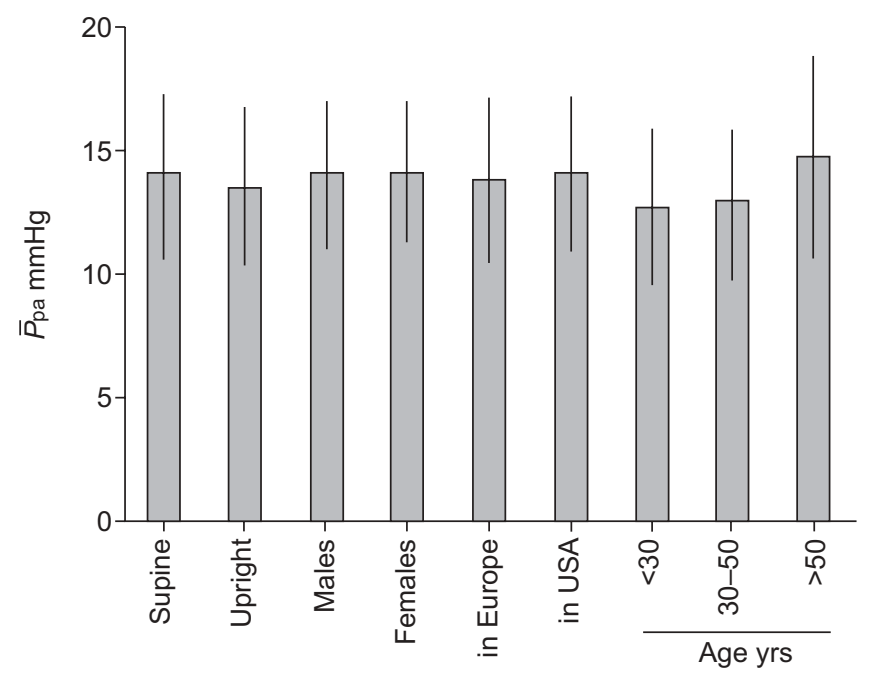

FIGURE 1. Mean pulmonary arterial pressure $\left(\bar{P}_{\mathrm{p} a}\right)$ of healthy subjects at rest according to different strata. Data are presented as mean \pm SD. 


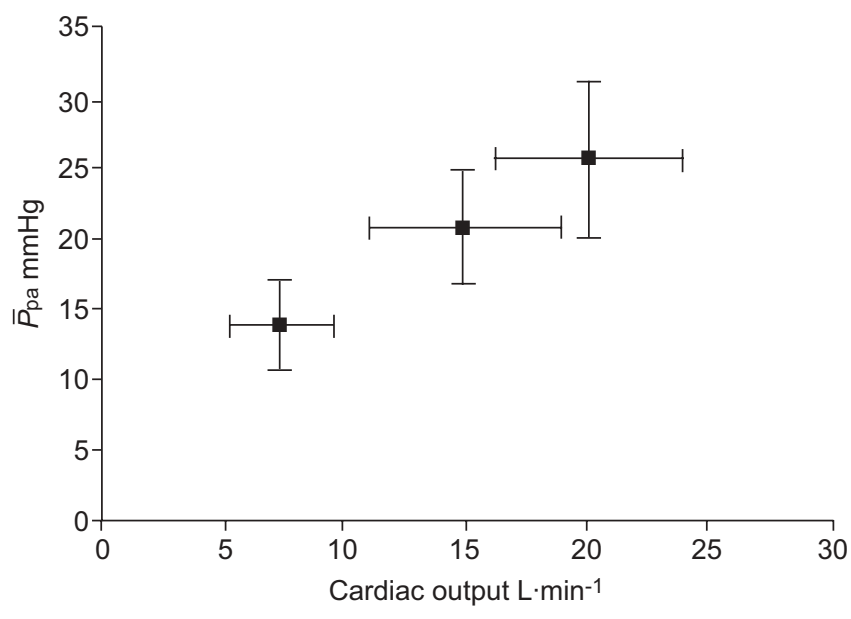

FIGURE 2. Mean pulmonary arterial pressure $(\bar{P} \mathrm{pa})$ and cardiac output in healthy subjects at rest, slight exercise and maximal exercise in an upright position. Data are presented as mean \pm SD. $n=193$.

reviewed. Resting pulmonary arterial wedge pressure (Ppaw) was independent of age $(7.7 \pm 3.0 \mathrm{mmHg}$ for individuals aged $\geqslant 50 \mathrm{yrs}$ versus $8.0 \pm 2.8 \mathrm{mmHg}$ for subjects aged $<50 \mathrm{yrs}$; $\mathrm{p}=0.61)$, but similarly to $\bar{P}$ pa, $P$ paw showed an age dependency during exercise, when individuals younger $(10.9 \pm 3.9 \mathrm{mmHg}$ at supine slight exercise) and older than $50 \mathrm{yrs}$ $(16.8 \pm 6.5 \mathrm{mmHg}$ with supine slight exercise) were compared $(\mathrm{p}<0.001)$ (online data supplement, tables E and F). Data on cardiac output and pulmonary vascular resistance were not always available and might not follow a Gaussian distribution. The mean \pm SD values given in table 1 should be interpreted with caution.

\section{Influence of sex, geographical origin, exercise method and position on Ppa}

Sex and the geographical origin of the data did not significantly influence resting and exercise $\bar{P}$ pa values (online data supplement, tables G-I) [13, 14, 16, 18, 19, 29, 35, 39, 43, 47].

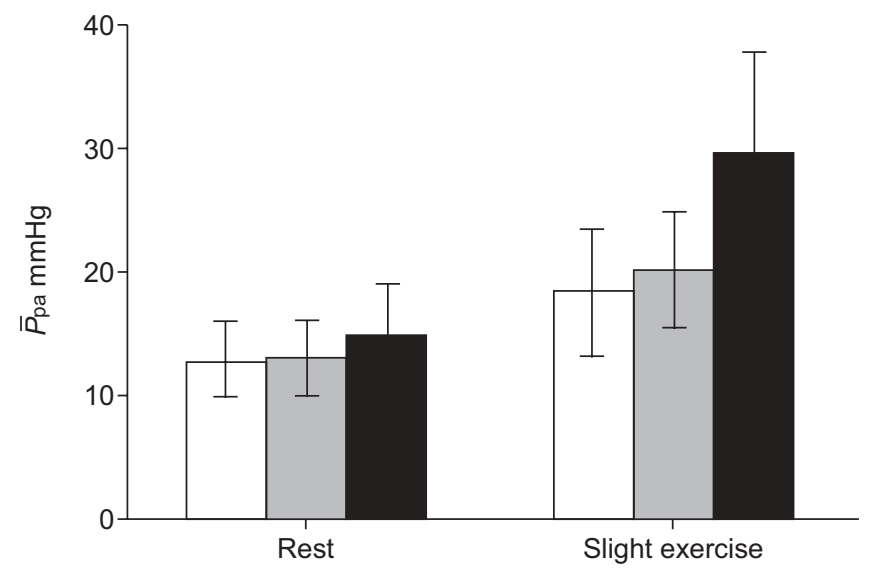

FIGURE 3. Mean pulmonary arterial pressure $\left(\bar{P}_{\mathrm{p} a}\right)$ during rest and slight supine exercise in healthy subjects aged 18-30 yrs ( $\square$; $n=144$ ), 30-50 yrs ( $\square$; $n=169)$ and $\geqslant 50$ yrs $(\mathbf{\square} ; n=91)$. Data are presented as mean \pm SD.
The type of exercise influenced the results. Measured on the treadmill, $[26,32,46,55] \bar{P}_{\text {pa }}$ at rest $(14.2 \pm 4.2 \mathrm{mmHg})$ and at slight exercise $(19.8 \pm 4.9 \mathrm{mmHg})$ was similar to cycle ergometry data, while during submaximal and maximal exercise

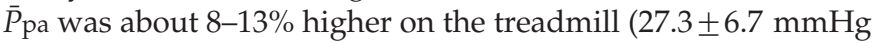
at maximal exercise resulting in an ULN of $40.7 \mathrm{mmHg}$; $=41$ ), than on the cycle ergometer $(24.0 \pm 6.4 \mathrm{mmHg}$ supine and $25.2 \pm 5.1 \mathrm{mmHg}$ upright).

Haemodynamic differences observed between the supine and upright position at rest and during exercise showed slightly decreased $\bar{P}$ pa and cardiac output and increased heart rate values in the upright compared with the supine position and were in agreement with previous reports (online data supplement, table J) [59].

\section{DISCUSSION}

We reviewed a substantial body of available data on pulmonary pressure values during rest and different levels of exercise in healthy volunteers. Only haemodynamic data obtained from right heart catheterisations were considered. With 1,187 included individuals, this is to our knowledge the largest survey to date of right heart catheterisation data in healthy individuals.

We stratified data for the most important factors, such as level of exercise, posture, sex, age, and geographical origin.

\section{Resting Pיpa}

Resting $\bar{P}_{\mathrm{pa}}$ is virtually independent of sex and geographical origin and is influenced slightly by age and posture. If a definition of mean+2SD is accepted for the ULN, the ULN for resting $\bar{P}_{\text {pa }}$ is $20.6 \mathrm{mmHg}(20.2 \mathrm{mmHg}$ in individuals aged $<50$ yrs). Historically, the threshold for PAH was defined as $25 \mathrm{mmHg}$ [60] and this value has been used in the current guidelines. In view of the results of the present analysis, it should be considered that the optimal threshold distinguishing between normal and elevated resting $\bar{P}_{\text {pa }}$ may be considerably lower. A $\bar{P}_{\text {pa }}$ of $20-25 \mathrm{mmHg}$ may represent clinically relevant pulmonary hypertension. In fact, even values above the 1SD limit $(17.3 \mathrm{mmHg})$ may have prognostic relevance as suggested by studies on patients with chronic obstructive pulmonary disease and lung fibrosis, where patients with $\bar{P}_{\text {pa }}>17-18 \mathrm{mmHg}$ had an unfavourable prognosis [6-8]. Until now, patients with a $\bar{P}_{\mathrm{pa}}<25 \mathrm{mmHg}$ were excluded from randomised controlled trials for PAH. Consequently, we do not know whether patients with $\bar{P}$ pa values of $20-25 \mathrm{mmHg}$ would benefit from targeted PAH therapies.

\section{Factors influencing $\overline{\mathrm{P}}$ pa during exercise}

$\bar{P}_{\text {pa }}$ during exercise is affected by workload. According to studies in which subjects were examined at multiple exercise levels (table 2), the increase in $\bar{P}_{\text {pa }}$ was comparable from rest to slight exercise and from slight to maximal exercise, and showed a linear relation to the increase in cardiac output.

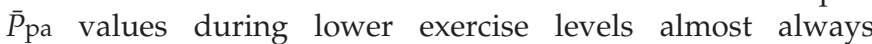
remained $<30 \mathrm{mmHg}$ (in subjects aged $<50 \mathrm{yrs}$ ), but $21 \%$ of the examined healthy individuals (aged $<50 \mathrm{yrs}$ ) surpassed the present threshold for $\mathrm{PAH}$ (i.e. $30 \mathrm{mmHg}$ ) during maximal exercise. 
Age substantially influences $\bar{P}$ pa values. At rest, the difference between age-groups is negligible. During slight exercise, differences become substantial, and the $\bar{P}_{\text {pa }}$ in subjects aged $>50$ yrs exceed the $30 \mathrm{mmHg}$ threshold in $\sim 47 \%$ of all cases.

Consequently, it may not be possible to define a single upper limit of normal $\bar{P}_{\text {pa }}$ that fits all individuals and all exercise levels, and so it may be difficult to incorporate exercise haemodynamics in the haemodynamic definition of $\mathrm{PH}$.

\section{Definition of normal ranges for $\overline{\mathrm{P}}$ pa}

With the assumption that the values follow a Gaussian distribution, it seems quite unlikely that a healthy individual aged $<50$ yrs would surpass the $25 \mathrm{mmHg} \bar{P}_{\text {pa }}$ threshold at rest (one person in 5,000), while this can be expected in 1 in 250 healthy subjects aged $\geqslant 50 \mathrm{yrs}$ (online data supplement, table K). However, even in young individuals, a rate of 0.0002 would translate into a prevalence of 200 per million, and would thus by far exceed current estimates of PAH prevalence (15-52 per million) [61, 62]. On the other hand, resting $\bar{P}_{\text {pa }}$ values $>17 \mathrm{mmHg}$ may indicate pathological conditions [6, 7]. This highlights the importance of clinical assessment as compared with focusing on haemodynamics only. Further prospective studies will be necessary to justify certain pulmonary arterial pressure thresholds for the definition of $\mathrm{PH}$.

The data of this review do not support the current threshold of $\bar{P}_{\text {pa }}$ during exercise. According to the reviewed data, nearly half of subjects aged $\geqslant 50$ yrs are expected to develop a $\bar{P}_{\text {pa }}$ $>30 \mathrm{mmHg}$ during slight exercise and about $20 \%$ of subjects aged $<50$ yrs are expected to exceed this value during maximal exercise (online data supplement, table K).

\section{Study limitations}

There are certain limitations to this analysis. Despite our effort to review all relevant studies, some published data may have been missed. The interpretation of the results of almost 1,200 subjects examined by right heart catheterisation under controlled conditions should nonetheless allow robust conclusions.

Although studies from three continents (Europe, North America and South America) were included, the population of a large part of the world was not represented. In addition, only studies conducted at sea level with normal oxygen tension were analysed.

There may be an overrepresentation of well-trained subjects due to recruitment bias; however, there was no indication that fitness level has an impact on $\bar{P}_{\text {pa. }}$. One study examined this question, by applying the same protocol to trained and untrained individuals [49]. It showed differences in heart rate and cardiac output, but not in $\bar{P}$ pa values between the groups, either at rest or during exercise.

Our data originate from normal-weight populations. These results may not apply to overweight subjects $[63,64]$.

In most studies, the zero level was set either $10 \mathrm{~cm}$ above the table level or $5 \mathrm{~cm}$ below the level of the sternum. A few studies used the mid-thoracic line for levelling. This might have altered the results slightly.

We accepted the statements in the reviewed studies that the volunteers were healthy, or that their diseases did not influence pulmonary haemodynamics, yet we cannot exclude the possibility that unidentified diseases influenced pulmonary pressure. Of the 72 study populations, five included some subjects with systemic arterial hypertension. $\bar{P}_{\text {pa values at rest }}$ and during exercise derived from these five studies showed no significant difference at rest or during exercise compared to those originating from studies excluding all subjects with systemic hypertension. Nevertheless we cannot be sure

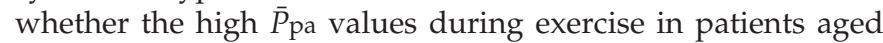
$\geqslant 50$ yrs might have been related partly to underlying diastolic dysfunction of the left ventricle.

\section{Conclusion}

The data from a large number of right heart catheterisations in healthy individuals suggest a normal mean pulmonary arterial pressure of $14.0 \pm 3.3 \mathrm{mmHg}$ at rest and an age-dependent increase during exercise that may exceed $30 \mathrm{mmHg}$, particularly in subjects aged $\geqslant 50$ yrs.

\section{STATEMENT OF INTEREST}

None declared.

\section{ACKNOWLEDGEMENTS}

J. Widimsky (Prague, Czech Republic) kindly provided the summary of a retrospective multicentre WHO study for the authors. We would like to thank E. Lamont (Dept of Pathology, Medical University of Graz, Graz, Austria) for careful linguistic revision of the manuscript.

\section{REFERENCES}

1 Simonneau G, Galie N, Rubin LJ, et al. Clinical classification of pulmonary hypertension. J Am Coll Cardiol 2004; 43: Suppl. S, 5S-12S.

2 Galie N, Torbicki A, Barst R, et al. Guidelines on diagnosis and treatment of pulmonary arterial hypertension. The Task Force on Diagnosis and Treatment of Pulmonary Arterial Hypertension of the European Society of Cardiology. Eur Heart J 2004; 25: 2243-2278.

3 Harris P, Heath D. Normal variations in pressure and flow. In Harris P, Heath D, eds. The Human Pulmonary Circulation. New York, Churchill Livingstone, 1986; pp. 149-160.

4 Naeije R. Pulmonary vascular function. In: Peacock A, Rubin LJ, eds. Pulmonary Circulation, 2nd Edn. London, Edward Arnold, 2004; pp. 3-13.

5 Widimsky J, Dixon H. Normal values of central hemodynamics at rest and during exercise. A preliminary report of a retrospective WHO study. In: Rulli V, Messin R, Denolin H. Normal Values in Adults Ergometry According to Age, Sex and Training. Rome, Soc. Europea di Cardiologia, 1980; pp. 177-195.

6 Hamada K, Nagai S, Tanaka S, et al. Significance of pulmonary arterial pressure and diffusion capacity of the lung as prognosticator in patients with idiopathic pulmonary fibrosis. Chest 2007; 131: 650-656.

7 Kessler R, Faller M, Fourgaut G, et al. Predictive factors of hospitalization for acute exacerbation in a series of 64 patients with chronic obstructive pulmonary disease. Am J Respir Crit Care Med 1999; 159: 158-164.

8 Weitzenblum E, Hirth C, Ducolone A, et al. Prognostic value of pulmonary artery pressure in chronic obstructive pulmonary disease. Thorax 1981; 36: 752-758.

9 Hickam JB, Cargill WH. Effect of exercise on cardiac output and pulmonary arterial pressure in normal persons and in patients with cardiovascular disease and pulmonary emphysema. J Clin Invest 1948; 27: 10-23.

10 Wagner PD, Gale GE, Moon RE, et al. Pulmonary gas exchange in humans exercising at sea level and simulated altitude. J Appl Physiol 1986; 61: 260-270. 
11 Riley RL, Himmelstein A, Morley HL, et al. Studies of the pulmonary circulation at rest and during exercise in normal individuals and in patients with chronic pulmonary disease. Am J Physiol 1948; 152: 372-382.

12 Dexter L, Whittenberger JL, Haynes FW, et al. Effect of exercise on circulatory dynamics of normal individuals. J Appl Physiol 1951; 3: 439-453.

13 Slonim NB, Ravin A, Balchum OJ, et al. The effect of mild exercise in the supine position on the pulmonary arterial pressure of five normal human subjects. J Clin Invest 1954; 33: 1022-1030.

14 Donald KW, Bishop JM, Cumming G, et al. The effect of exercise on the cardiac output and circulatory dynamics of normal subjects. Clin Sci (Lond) 1955; 14: 37-73.

15 Freedman ME, Snider GL, Brostoff $\mathrm{P}$, et al. Effect of training on response of cardiac output to muscular exercise in athletes. J Appl Physiol 1955; 8: 37-47.

16 Sancetta SM, Rakita L. Response of pulmonary artery pressure and total pulmonary resistance of untrained, convalescent man to prolonged mild steady state exercise. J Clin Invest 1957; 36: 1138-1149.

17 Reymond C, Desbaillets P, Baudraz B, et al. Epreuve d'effort et catheterisme cardiaque [Exercise test and cardiac catheterization]. Cardiologia 1957; 30: 259-278.

18 Fishman AP, Fritts HW Jr, Cournand A. Effects of acute hypoxia and exercise on the pulmonary circulation. Circulation 1960; 22: 204-215.

19 Holmgren A, Jonsson B, Sjostrand T. Circulatory data in normal subjects at rest and during exercise in recumbent position, with special reference to the stroke volume at different work intensities. Acta Physiol Scand 1960; 49: 343-363.

20 Bevegard S, Holmgren A, Jonsson B. The effect of body position on the circulation at rest and during exercise, with special reference to the influence on the stroke volume. Acta Physiol Scand 1960; 49: 279-298.

21 Widimsky J, Berglund E, Malmberg R. Effect of repeated exercise on the lesser circulation. J Appl Physiol 1963; 18: 983-986.

22 Bevegard S, Holmgren A, Jonsson B. Circulatory studies in well trained athletes at rest and during heavy exercise. With special reference to stroke volume and the influence of body position. Acta Physiol Scand 1963; 57: 26-50.

23 Granath A, Jonsson B, Strandell T. Circulation in healthy old men, studied by right heart catheterization at rest and during exercise in supine and sitting position. Acta Med Scand 1964; 176: 425-446.

24 Granath A, Strandell T. Relationships between cardiac output, stroke volume and intracardiac pressures at rest and during exercise in supine position and some anthropometric data in healthy old men. Acta Med Scand 1964; 176: 447-466.

25 Ekelund LG, Holmgren A. Circulatory and respiratory adaptation, during long-term, non-steady state exercise, in the sitting position. Acta Physiol Scand 1964; 62: 240-255.

26 Damato AN, Galante JG, Smith WM. Hemodynamic response to treadmill exercise in normal subjects. J Appl Physiol 1966; 21: 959-966.

27 Banchero N, Sime F, Penaloza D, et al. Pulmonary pressure, cardiac output, and arterial oxygen saturation during exercise at high altitude and at sea level. Circulation 1966; 33: 249-262.

28 Ekelund LG, Holmgren A. Central hemodynamics during exercise. Circulat Res 1967; 20/21: Suppl. 1, I33-I43.

29 Parker JO, Di Giorgi S, West RO. A hemodynamic study of acute coronary insufficiency precipitated by exercise. With observations on the effects of nitroglycerin. Am J Cardiol 1966; 17: 470-483.

30 Gurtner HP, Keller MF, Salzmann C. Die Hämodynamic gesunder Studenten in Ruhe und bei abgestufter Belastung [The hemodynamics of healthy students at rest and under graduated work load]. Med Thorac 1967; 24: 162-170.

$31 \mathrm{Yu}$ PN, Murphy GW, Schreiner BF Jr, et al. Distensibility characteristics of the human pulmonary vascular bed. Study of the pressure-volume response to exercise in patients with and without heart disease. Circulation 1967; 35: 710-723.
32 Epstein SE, Beiser GD, Stampfer M, et al. Characterization of the circulatory response to maximal upright exercise in normal subjects and patients with heart disease. Circulation 1967; 35: 1049-1062.

33 Harris P, Segel N, Bishop JM. The relation between pressure and flow in the pulmonary circulation in normal subjects and in patients with chronic bronchitis and mitral stenosis. Cardiovasc Res 1968; 2: 73-83.

34 Ekelund LG. Circulatory and respiratory adaptation during prolonged exercise in the supine position. Acta Physiol Scand 1966; 68: 382-396.

35 Emirgil C, Sobol BJ, Campodonico S, et al. Pulmonary circulation in the aged. J Appl Physiol 1967; 23: 631-640.

36 Alexander JK, Hartley LH, Modelski M, et al. Reduction of stroke volume during exercise in man following ascent to $3,100 \mathrm{~m}$ altitude. J Appl Physiol 1967; 23: 849-858.

37 Messin R, Degre S, Demaret B, et al. The effect of age on pulmonary circulation in normal subjects. Prog Resp Res 1970; 5: 385-394.

38 Stanek V, Jebavy P, Hurych J, et al. Central haemodynamics during supine exercise and pulmonary artery occlusion in normal subjects. Bull Physiopathol Respir (Nancy) 1973; 9: 1203-1217.

39 Gurtner HP, Walser P, Fässler B. Normal values for pulmonary hemodynamics at rest and during exercise in man. Prog Resp Res 1975; 9: 295-315.

40 Most E, Klempt HW, Korkisch E, et al. Das Verhalten des Pulmonalarterien- und Pulmonalkapillardruckes bei einstufiger Ergometerbelastung [The behaviour of pulmonary arterial pressure and pulmonary capillary wedge pressure during exercise]. Herz/Kreisl 1975; 7: 399-405.

41 Kubicek F, Zwick H. Pulmonalarteriendruck unter ansteigender Ergometerbelastung [The normal range of the pulmonary artery pressure during ergometrical exercise]. Med Klin 1976; 71: 409-413.

42 Keller R, Kopp C, Zutter W, et al. Der Lungenkreislauf als leistungsbegrenzender Faktor bei Patienten [Pulmonary circulation as a limiting factor in physical work capacity]. Pneumonologie 1976; 5: Suppl, 27-39.

43 Haerten K, Both A, Krelhaus W, et al. Die Hämodynamic des kleinen Kreislaufs bei Herzgesunden unter mehrstufiger Ergometerbelastung [Hemodynamics of the pulmonary circulation during a multistep exercise test in healthy subjects]. Med Welt 1976; 27: 2386-2388.

44 Kubicek F, Gaul G. Comparison of supine and sitting body position during a triangular exercise test. I. Experiences in healthy subjects. Eur J Appl Physiol Occup Physiol 1977; 36: 275-283.

45 Thadani U, Parker JO. Hemodynamics at rest and during supine and sitting bicycle exercise in normal subjects. Am J Cardiol 1978; 41: 52-59.

46 Hossack KF, Bruce RA, Green B, et al. Maximal cardiac output during upright exercise: approximate normal standards and variations with coronary heart disease. Am J Cardiol 1980; 46: 204-212.

47 Harzbecker K, Krause M, Mährlein W. Referenzwerte der pulmonalen Hämodynamik in Ruhe und unter Ergometerbelastung in sitzender Position [Reference values of the pulmonary hemodynamics at rest and during exercise in the sitting position]. Dtsch Gesundh Wes 1981; 36: 498-502.

48 Wenzel D, Scheuler D, Schiller W. Referenzwerte der pulmonalen Hämodynamik in Ruhe und unter Ergometerbelastung in liegender Position [Reference values of the pulmonary hemodynamics at rest and during exercise in the supine position]. Dtsch Gesundh Wes 1982; 37: 840-874.

49 Lehmann $\mathrm{M}$, Ruhle $\mathrm{K}$, Schmid $\mathrm{P}$, et al. Hämodynamik, Plasmakatecholaminverhalten und beta-Adrenozeptorendichte bei Trainierten, Untrainierten und Herzinsuffizienten [Hemodynamics, plasma catecholamine behavior and beta-adrenergic receptor density in trained and untrained subjects and cardiac insufficiency patients]. Z Kardiol 1983; 72: 529-536. 
50 Ehrsam RE, Perruchoud A, Oberholzer M, et al. Influence of age on pulmonary haemodynamics at rest and during supine exercise. Clin Sci (Lond) 1983; 65: 653-660.

51 Higginbotham MB, Morris KG, Williams RS, et al. Regulation of stroke volume during submaximal and maximal upright exercise in normal man. Circ Res 1986; 58: 281-291.

52 Reeves JT, Groves BM, Sutton JR, et al. Operation Everest II: preservation of cardiac function at extreme altitude. J Appl Physiol 1987; 63: 531-539.

53 Groves BM, Reeves JT, Sutton JR, et al. Operation Everest II: elevated high-altitude pulmonary resistance unresponsive to oxygen. J Appl Physiol 1987; 63: 521-530.

54 Janosi A, Apor P, Hankoczy J, et al. Pulmonary artery pressure and oxygen consumption measurement during supine bicycle exercise. Chest 1988; 93: 419-421.

55 Hossack KF, Adair OV, Crowley ST. Atrial natriuretic factor production during upright exercise. Cardiology 1990; 77: 433-442.

56 Lonsdorfer-Wolf E, Richard R, Doutreleau S, et al. Pulmonary hemodynamics during a strenuous intermittent exercise in healthy subjects. Med Sci Sports Exerc 2003; 35: 1866-1874.

57 Stanek V, Widimsky J, Hurych J. The effect of age on the pressureflow relationship and on the capacity of the pulmonary vascular bed with special reference to the condition of high flow. Prog Resp Res 1970; 5: 375-384.

58 Degre S, de Coster A, Messin R, et al. Normal pulmonary pressure-flow relationship during exercise in the sitting position. Int Z Angew Physiol 1972; 31: 53-59.

59 Reeves JT, Dempsey JA, Grover RF. Pulmonary circulation during exercise. In: Weir EK, Reeves JT, eds. Pulmonary Vascular Physiology and Physiopathology. New York, Marcel Dekker, 1989; pp. 107-133.

60 Hatano S, Strasser T. Primary Pulmonary Hypertension: Report on a WHO Meeting. Geneva, World Health Organization, 1973.

61 Humbert M, Sitbon O, Chaouat A, et al. Pulmonary arterial hypertension in France: results from a national registry. Am J Respir Crit Care Med 2006; 173: 1023-1030.

62 Peacock AJ, Murphy NF, McMurray JJ, et al. An epidemiological study of pulmonary arterial hypertension. Eur Respir J 2007; 30: 104-109.

63 de Divitiis O, Fazio S, Petitto M, et al. Obesity and cardiac function. Circulation 1981; 64: 477-482.

64 Slany J, Mosslacher H, Irsigler K. Beeinflußt Adipositas die Herzfunktion? [Does obesity have an effect on heart function?] Z Kardiol 1975; 64: 851-862. 